Article

\title{
Green Conversion of Agroindustrial Wastes into Chitin and Chitosan by Rhizopus arrhizus and Cunninghamella elegans Strains
}

Lúcia Raquel Ramos Berger ${ }^{1,2}$, Thayza Christina Montenegro Stamford ${ }^{3}$, Thatiana Montenegro Stamford-Arnaud ${ }^{3}$, Sergio Roberto Cabral de Alcântara ${ }^{4}$, Antonio Cardoso da Silva ${ }^{2}$, Adamares Marques da Silva ${ }^{1,2}$, Aline Elesbão do Nascimento ${ }^{2}$ and Galba Maria de Campos-Takaki ${ }^{2, *}$

1 Post-Graduation Program in Biological Sciences, Federal University of Pernambuco, Recife, PE 50670-420, Brazil; E-Mails: quelberger@hotmail.com (L.R.R.B.); adamaresmarques@hotmail.com (A.M.S.)

2 Nucleus of Research in Environmental Science and Biotechnology (NPCIAMB), Catholic University of Pernambuco, Recife, PE 50050-590, Brazil; E-Mails: antoniocardoso2000@yahoo.com.br (A.C.S.); elesbao@unicap.br (A.E.N.)

3 Department of Tropical Medicine, Center of Health Sciences, Federal University of Pernambuco, Recife, PE 50670-420, Brazil; E-Mails: thayzastamford@yahoo.com.br (T.C.M.S.); thatianaarnaud@hotmail.com (T.M.S.-A.)

4 Post-Graduation Program in Development and Environment, Federal University of Paraíba, Campus 1, João Pessoa, PB 58051-900, Brazil; E-Mail: pohlux@gmail.com

* Author to whom correspondence should be addressed; E-Mail: galba_takaki@yahoo.com.br; Tel.: +55-81-2119-4017; Fax: +55-81-2119-4043.

Received: 12 January 2014; in revised form: 31 March 2014 / Accepted: 25 April 2014 / Published: 21 May 2014

\begin{abstract}
This article sets out a method for producing chitin and chitosan by Cunninghamella elegans and Rhizopus arrhizus strains using a green metabolic conversion of agroindustrial wastes (corn steep liquor and molasses). The physicochemical characteristics of the biopolymers and antimicrobial activity are described. Chitin and chitosan were extracted by alkali-acid treatment, and characterized by infrared spectroscopy, viscosity and X-ray diffraction. The effectiveness of chitosan from C. elegans and $R$. arrhizus in inhibiting the growth of Listeria monocytogenes, Staphylococcus aureus, Pseudomonas aeruginosa, Salmonella enterica, Escherichia coli and Yersinia enterocolitica were evaluated by determining the minimum inhibitory concentrations (MIC) and the minimum bactericidal
\end{abstract}


concentrations (MBC). The highest production of biomass $(24.60 \mathrm{~g} / \mathrm{L})$, chitin $(83.20 \mathrm{mg} / \mathrm{g})$ and chitosan $(49.31 \mathrm{mg} / \mathrm{g})$ was obtained by R. arrhizus. Chitin and chitosan from both fungi showed a similar degree of deacetylation, respectively of $25 \%$ and $82 \%$, crystallinity indices of $33.80 \%$ and $32.80 \%$ for chitin, and $20.30 \%$ and $17.80 \%$ for chitosan. Both chitin and chitosan presented similar viscosimetry of $3.79-3.40 \mathrm{cP}$ and low molecular weight of $5.08 \times 10^{3}$ and $4.68 \times 10^{3} \mathrm{~g} / \mathrm{mol}$. They both showed identical MIC and MBC for all bacteria assayed. These results suggest that: agricultural wastes can be produced in an environmentally friendly way; chitin and chitosan can be produced economically; and that chitosan has antimicrobial potential against pathogenic bacteria.

Keywords: Zygomycetes; polymer; agroindustrial waste; antibacterial activity

\section{Introduction}

Chitosan is a natural co-polymer of chitin, comprising units of 2-amino-2-desoxi-D-glycopyranose and of 2-acetamide-2-desoxi-D-glycopyranose interconnected by glycosidic bonds $\beta-1.4$ in variable proportions. The first type of unit is frequently present in chitosan [1]. Chitin is present as a structural element in the exoskeleton of crustaceans, mollusks, annelids, coelenterates and insects. It is also a major component of the fungal cell wall, particularly of Zygomycetes [2,3]. Chitosan is a cationic and linear polymer, naturally found in the cell wall of fungi, mainly in the Mucorales order. Although the main commercial source of chitosan is crustacean shells, some studies have proposed that cultivating selected fungi could provide an effective source of chitosan for industrial applications $[1,2,4]$.

Recent advances in fermentation technology for the fungal production of chitin and chitosan have received worldwide attention and some studies suggest that many of the problems encountered when extracting biopolymers in a traditional way can be overcome [5,6]. The use of chitin and chitosan from fungi biomass has great advantages, such as independence from seasonal factors, wide scale production, simultaneous extraction of the polymers, and the fact that the process of extracting chitosan from the biomass of fungi is simple and cheap, resulting in reductions in the time and cost of production. Moreover, this strategy avoids protein contamination, particularly from proteins that could cause allergic reactions in individuals with shellfish allergies $[4,7,8]$.

The biowaste from some industrial by-products such as molasses, corn steep liquor and cassava wastewater can be used as very economical nutritional sources when cultivating fungi. This alternative favors obtaining a byproduct with high added value as well as decreasing total production costs $[9,10]$. Molasses from cane sugar, a byproduct of the sugar industry, has a large amount of fermentable sugar and is considered a waste that is easy to handle, costs little and has great potential and many applications at an industrial level. By virtue of its composition, molasses is used mainly as a source of carbon and energy but it is necessary to supplement it with nitrogen and some minerals, especially phosphorus and magnesium [11]. Corn steep liquor, a residue from the corn processing industry, has a large amount of amino acids, vitamins and the minerals necessary to cultivate microorganisms [2]. Thus substrates of molasses and corn steep liquor may be considered as low-cost 
alternatives that meet the nutrient and energy (carbon, hydrogen, oxygen and nitrogen) requirements for cultivating any microorganism.

Chitin and chitosan have emerged as among the most promising functional materials to choose from for various modern bio-based industrial applications. For example, they are used by the cosmetics, pharmaceutical and food industries, the agricultural and environmental sectors as well as to treat waste water. Characteristics, such as their being non-toxic, biodegradable, biocompatible, antimicrobially active, environmentally safe and easy to obtain, favor their current and future applicability [12,13].

The antimicrobial activity of chitosan has been pointed out as one of its most promising properties. This activity depends on its molecular weight, degree of deacetylation and the method used to obtain the polymer [14,15]. This is also regarded as one of the most interesting properties of chitosan [16]. Several researchers demonstrated that this polysaccharide has antimicrobial action in a great variety of microorganisms, including gram-positive bacteria and various species of yeast $[1,17,18]$. Moreover, chitosan has numerous advantages over other chemical disinfectants since it possesses a stronger antimicrobial activity, a broader range of activity, a higher antibacterial activity even at low concentrations, and a lower toxicity towards mammalian cells than other molecules [12].

Therefore, this article puts forward a way to optimize the production of chitin and chitosan by Cunninghamella elegans and Rhizopus arrhizus using two agroindustrial wastes, namely, corn steep liquor and molasses, as alternative low cost sources of carbon and nitrogen. The physicochemical characteristics and antimicrobial activity of the chitin and chitosan synthesized are also described.

\section{Results and Discussion}

\subsection{Comparative Influence of Molasses and Corn Steep Liquor on the Production of Biomass,}

\section{Chitin and Chitosan by C. elegans and R. arrhizus}

The influence of different concentrations of molasses and corn steep liquor on the yields of biomass, chitin and chitosan by $C$. elegans and $R$. arrhizus was observed in this study. Table 1 presents the comparative analysis of the results obtained in each assay of the $2^{2}$ factorial designs. Molasses and corn steep liquor in the highest concentrations presented a directly proportional effect on the increase in biomass production for both fungi. The best yields of biomass by C. elegans, 16.00 and $14.47 \mathrm{~g} \cdot \mathrm{L}^{-1}$, and $R$. arrhizus, 24.60 and $21.00 \mathrm{~g} \cdot \mathrm{L}^{-1}$, were obtained in Assay 4 (4.00\% molasses, 8.00\% corn steep liquor) and Assay 6 (2.50\% molasses, 5.00\% corn steep liquor), respectively, which had the highest concentrations of molasses and corn steep liquor. On the other hand, Assay 2 (4\% molasses, $2 \%$ corn steep liquor), in which the molasses concentration is twice as high as the corn steep liquor concentration, provided the best yields of chitin by $C$. elegans $\left(72.29 \mathrm{mg} \cdot \mathrm{g}^{-1}\right)$ and $R$. arrhizus $\left(83.20 \mathrm{mg} \cdot \mathrm{g}^{-1}\right)$. The pure experimental error was calculated from four replicates run corresponding to a central point of the complete factorial (Assays 5-8) as control.

The highest yields of chitosan, 26.29 and $33.13 \mathrm{mg} \cdot \mathrm{g}^{-1}$ from C. elegans, and $49.31^{1}$ and $40.67 \mathrm{mg} \cdot \mathrm{g}^{-1}$ from $R$. arrhizus were presented in culture medium 1, which had the lowest molasses (1\%) and corn steep liquor $(2 \%)$ concentrations, and in the central point with intermediate concentrations $(2.5 \%$ molasses, 5\% corn steep liquor) of these substrates, respectively. Therefore, R. arrhizus presented 
biomass and chitosan yields that were $30 \%$ higher compared to those obtained by $C$. elegans. The yield of chitin by $R$. arrhizus was also $13 \%$ higher than the yield obtained by $C$. elegans.

Table 1. Biomass, chitin and chitosan produced by $C$. elegans and $R$. arrhizus in each assay with different concentrations of molasses and corn steep liquor varied symmetrically around the central point according to the $2^{2}$ factorial designs.

\begin{tabular}{c|cc|cc|cc}
\hline \multirow{2}{*}{ Assays } & \multicolumn{2}{|c|}{ Biomass $\left(\mathbf{g} \cdot \mathbf{L}^{-\mathbf{1}}\right)$} & \multicolumn{2}{c|}{ Chitin $\left(\mathbf{m g} \cdot \mathbf{g}^{-\mathbf{1}}\right)$} & \multicolumn{2}{c}{ Chitosan $\left(\mathbf{m g} \cdot \mathbf{g}^{-\mathbf{1}}\right)$} \\
\cline { 2 - 7 } & C. elegans & R. arrhizus & C. elegans & R. arrhizus & C. elegans & R. arrhizus \\
\hline 1 & 7.41 & 8.25 & 64.96 & 45.72 & 26.29 & 49.31 \\
2 & 9.53 & 13.15 & 72.29 & 83.20 & 21.40 & 31.83 \\
3 & 7.93 & 17.50 & 70.40 & 57.40 & 25.63 & 20.14 \\
4 & 16.00 & 24.60 & 50.00 & 56.46 & 17.40 & 25.87 \\
5 & 14.47 & 18.00 & 59.09 & 73.29 & 28.33 & 37.67 \\
6 & 13.61 & 21.00 & 63.00 & 70.48 & 26.84 & 40.67 \\
7 & 13.58 & 20.60 & 69.11 & 70.53 & 33.13 & 39.00 \\
8 & 13.90 & 19.30 & 60.40 & 69.23 & 29.43 & 38.15 \\
\hline
\end{tabular}

There was a decrease in the $\mathrm{pH}$ (data not shown) from 6.0 (initial $\mathrm{pH}$ ) to 5.6 and 4.4 at the end of growth from $R$. arrhizus and C. elegans respectively. Similar results were observed by Santos et al. [10]. The influence of the culture medium $\mathrm{pH}$ in the biomass yield was observed by Nwe et al. [19] and Nwe and Stevens [20] who also noted that slightly acidic $\mathrm{pH}$ values are more favorable to the fungal growth. The low $\mathrm{pH}$ is optimal for the activity of chitin deacetylase and consequently favors the enzymatic deacetylation of chitin into chitosan, thereby increasing the yield of this biopolymer [21].

Bioprocesses are dependent on culture media being under appropriate and favorable conditions for the maintenance of microorganisms if they are to express their biotechnological potential [22]. Therefore, it was the specific concentrations of molasses and corn steep that provided the conditions for obtaining satisfactory yields of biomass, chitin and chitosan by $C$. elegans and $R$. arrhizus when compared to the values presented in the literature (Table 2). The results obtained in this study compared with the yields of biomass, chitin and chitosan by other microorganisms prove that the content of these biopolymers depends on the fungal strains, the age of the mycelia, the culture medium, the growth conditions and the extraction method used for extracting chitin and chitosan [23,24].

The alteration of culture conditions can increase the production of chitin deacetylase, the enzyme responsible for the bio-conversion of chitin to chitosan; and consequently it can influence the synthesis of the cell wall of a fungus and thus improve chitosan productivity [25].

A Pareto chart was used to show the effect of the independent variables of molasses and corn steep liquor on the production of biomass, chitin and chitosan by C. elegans and R. arrhizus. This statistical analysis has proved effective in assessing the influence of independent variables while seeking to optimize a specific result [5].

The Pareto charts (Figure 1A,B) show the positive effect of the molasses and corn steep liquor, including the interaction of these two independent variables, on the biomass production by both fungi, as also observed in Table 1, Assay 4 (4.00\% molasses, 8.00\% corn steep liquor) which had the highest concentrations of these variables and biomass production. 
Table 2. Biomass, chitin and chitosan production by C. elegans and R. arrhizus grown on agroindustrial waste compared with results obtained by other studies in the literature.

\begin{tabular}{cccccc}
\hline Microorganism & Substrate & $\begin{array}{c}\text { Biomass } \\
\left(\mathbf{g} \cdot \mathbf{L}^{-1}\right)\end{array}$ & $\begin{array}{c}\text { Chitin } \\
\left(\mathbf{m g} \cdot \mathbf{g}^{-1}\right)\end{array}$ & $\begin{array}{c}\text { Chitosan } \\
\left(\mathbf{m g} \cdot \mathbf{g}^{-\mathbf{1}}\right)\end{array}$ & Reference \\
\hline C. elegans & $\begin{array}{c}\text { Corn steep liquor } \\
\text { and molasses }\end{array}$ & 16.00 & 72.29 & 33.13 & This study \\
\hline R. arrhizus & $\begin{array}{c}\text { Corn steep liquor } \\
\text { and molasses }\end{array}$ & 24.60 & 83.20 & 49.31 & This study \\
\hline R. arrhizus & $\begin{array}{c}\text { Corn steep liquor and } \\
\text { cassava wastewater }\end{array}$ & 8.80 & 54.38 & 20.51 & {$[2]$} \\
\hline C. elegans & Coconut water & 2.19 & 389 & 129 & {$[2]$} \\
\hline R. arrhizus & Corn steep liquor 4\% & 13.00 & 30.40 & 12.85 & {$[26]$} \\
\hline Mucor circinelloides & Yam bean & 20.70 & 500 & 64 & {$[4]$} \\
\hline C. elegans & Yam bean & 24.30 & 440 & 66 & {$[8]$} \\
\hline Absidia corymbifera & Candy effluent, corn & 12.68 & $12.89(\%)$ & $52.71(\%)$ & {$[22]$} \\
\hline
\end{tabular}

Figure 1. Pareto charts showing the effect of the independent variables, corn steep liquor and molasses, on the biomass production by R. arrhizus (A) and C. elegans (B).

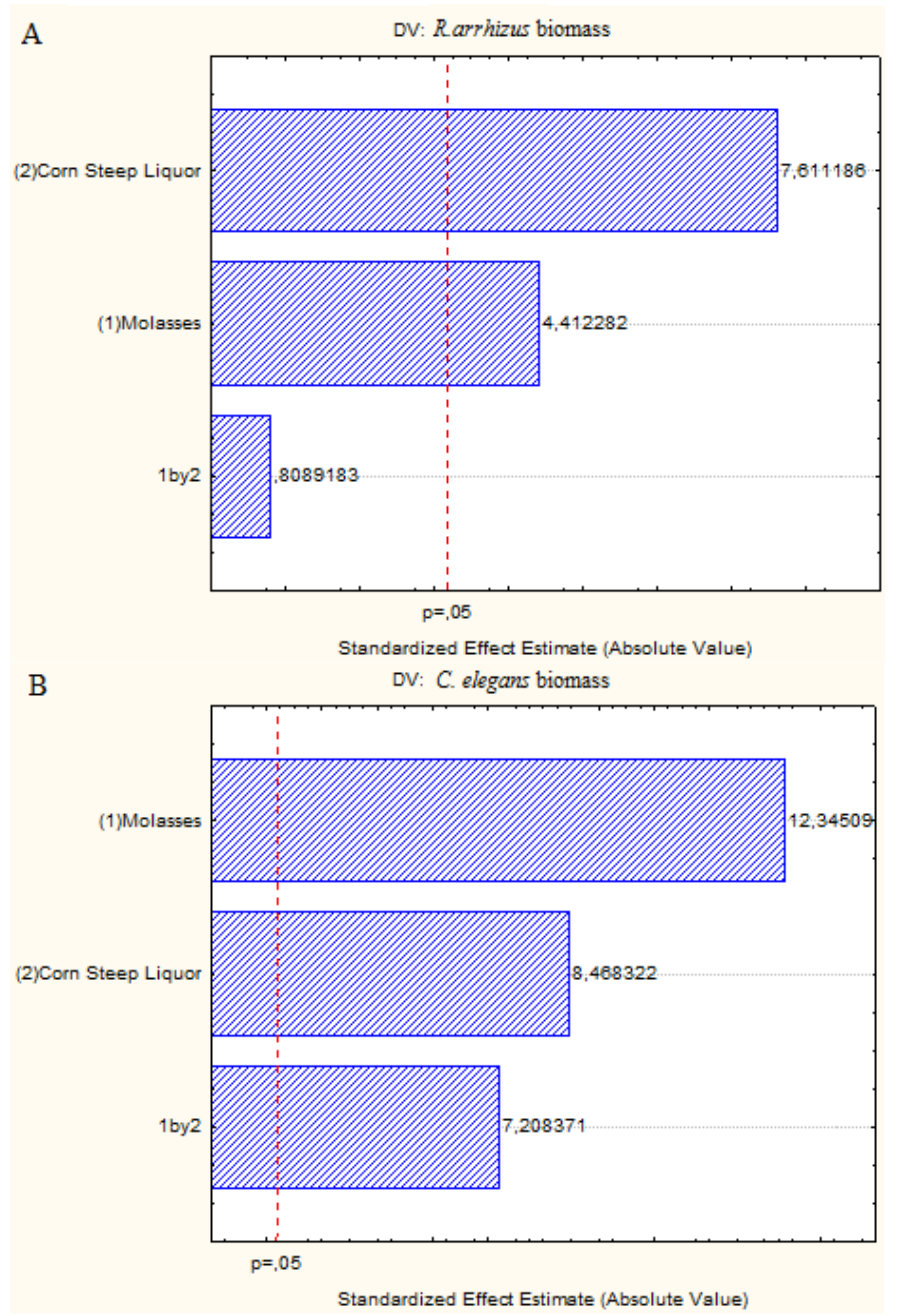


In Figure 2A, the Pareto charts also confirm the positive influence of molasses and the negative influences of corn steep liquor and the interaction between these variables on the production of chitin by $R$. arrhizus. The same result was obtained in Assay 2 (4\% molasses, $2 \%$ corn steep liquor), which provided the best yields of chitin with only the molasses in the highest concentrations. The Pareto chart, Figure 2B shows that lower concentrations of molasses and corn steep liquor favor the increase of chitin produced by $C$. elegans. The same result occurred in Assays 2 and 3 of the factorial design which presented the highest chitin yields for this fungus grown in low concentrations of corn steep liquor (Assay 2) or molasses (Assay 3).

Figure 2. Pareto charts showing the effect of the independent variables, corn steep liquor and molasses, on the chitin yield by R. arrhizus (A) and C. elegans (B).

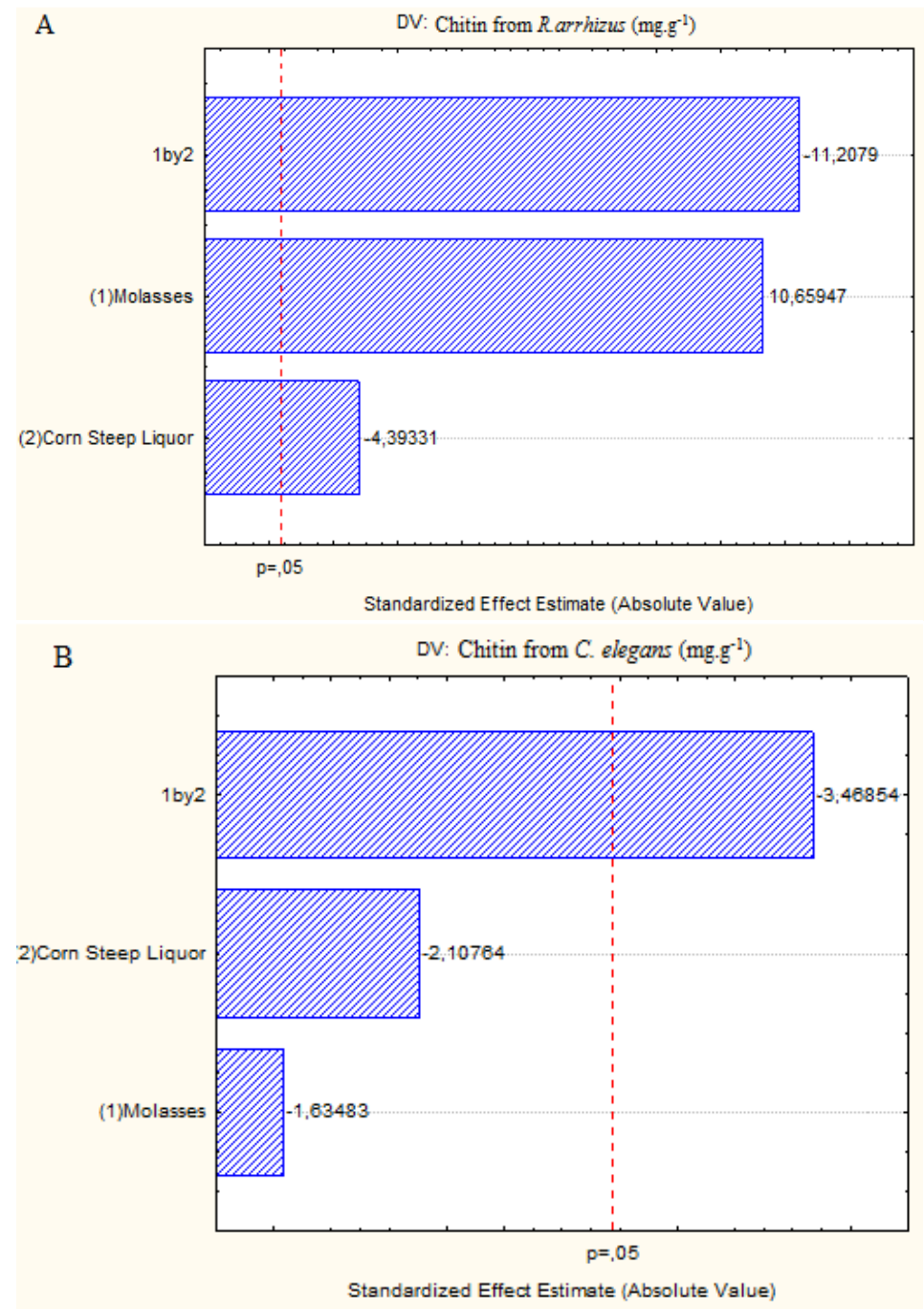

The results for chitosan shown in Table 1 were also corroborated by Figure 3, which shows the negative effect on chitosan production by $C$. elegans when these substrates are increased. The decrease in the concentrations of molasses or corn steep liquor, or the increase in these two substrates simultaneously in the culture medium promote a higher production of chitosan by $R$. arrhizus. However, higher concentrations of corn steep liquor and molasses than those used at the central point shown do not favor the production of chitosan (Assay 4, Table 1). 
Figure 3. Pareto charts showing the effect of the independent variables, corn steep liquor and molasses, on the chitosan yield by $R$. arrhizus (A) and C. elegans (B).

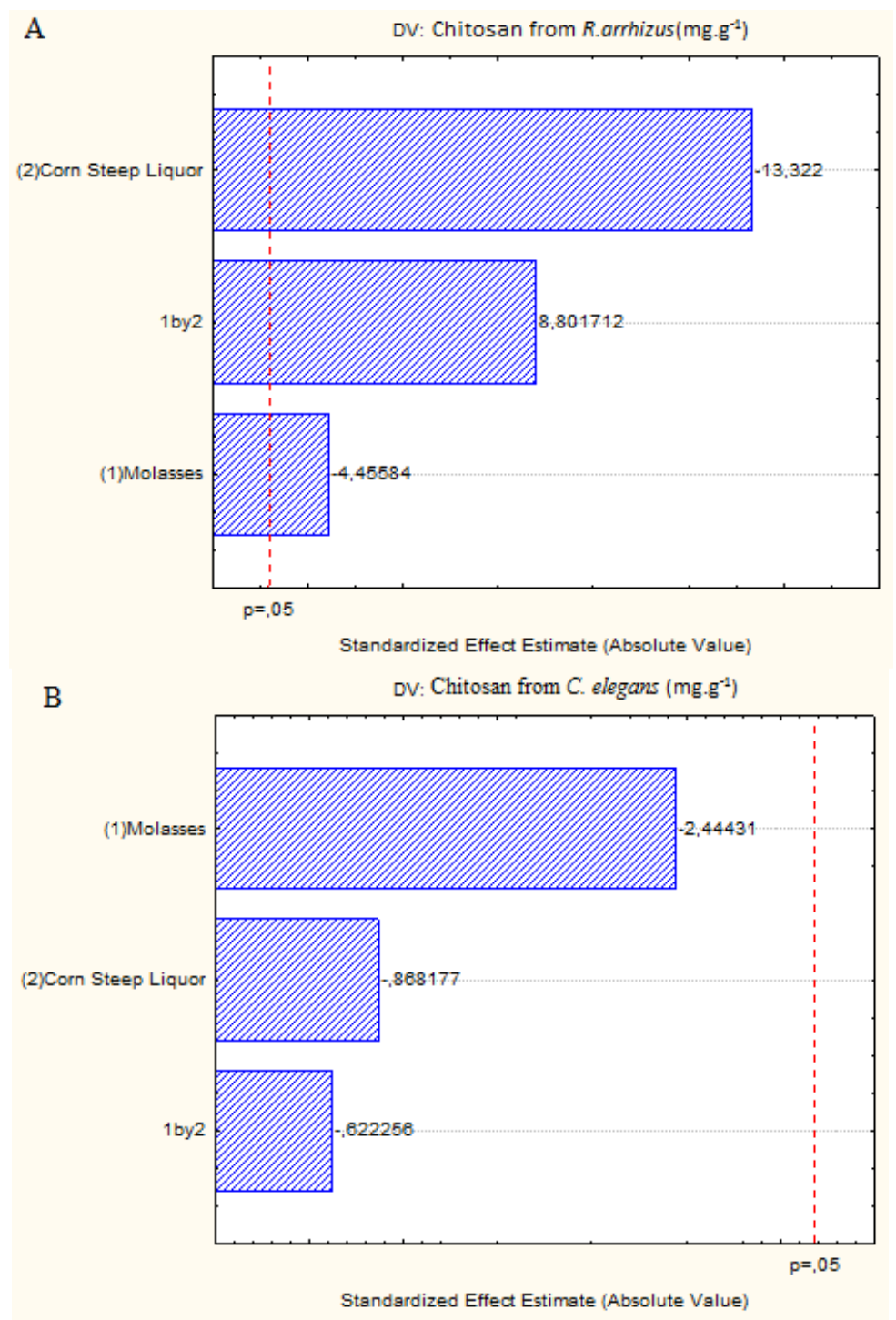

The contour curves (Figures 4 and 5) showed the optimize chitosan production by Rhizopus arrhizus and Cunninghamella elegans using corn steep liquor of (2\%) and molasses (1\%) medium.

The analysis of these results suggests that there is an economic culture medium, with specific concentrations of molasses and corn steep liquor as sources of carbon and nitrogen, for obtaining better yields of biomass, chitin and chitosan by $C$. elegans and $R$. arrhizus. Thus, probably to obtain better biomass production by these fungi it would be necessary to increase the concentration of molasses and corn steep liquor. From these fungi, greater chitin yields could be obtained using a culture medium with higher concentrations of molasses and lower concentrations of corn steep liquor. Furthermore, an increase in chitosan production could be achieved using values of molasses or corn steep liquor below the lowest levels of these substrates tested or intermediate concentrations. These large influences of culture conditions and nutritional sources for obtaining satisfactory yields of microbial chitosan were also observed by Pochanavanich and Suntornsuk [24] and Nadarajah et al. [27]. 
Figure 4. Surface response to chitosan production by Rhizopus arrhizus related to interaction of molasses and corn steep liquor.

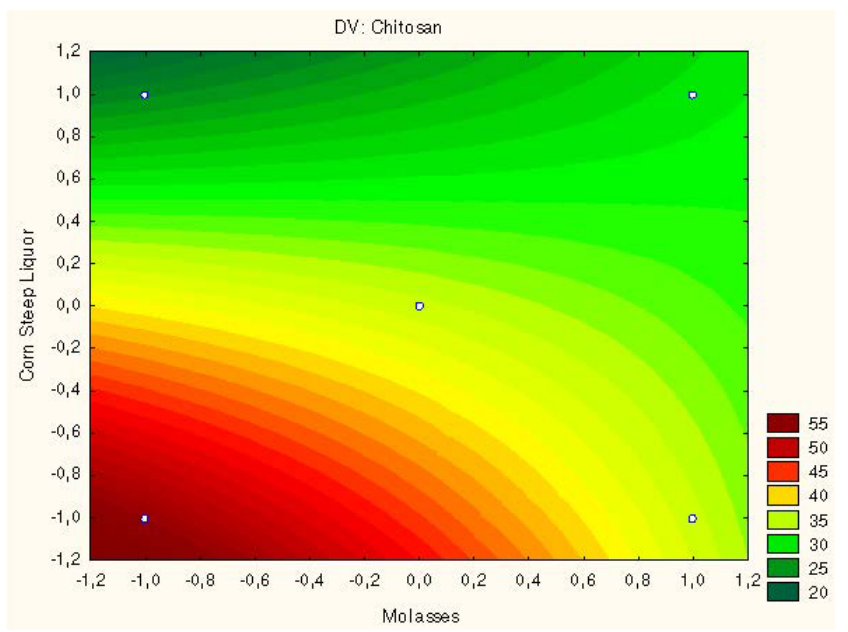

Figure 5. Surface response to chitosan production by Cunninghamella elegans related to interaction of molasses and corn steep liquor substrates.

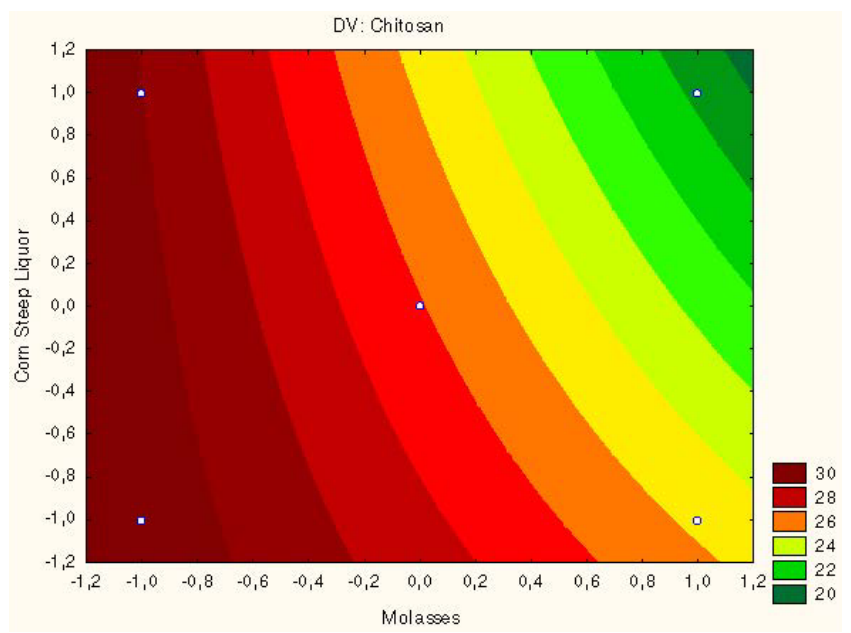

Other studies also show increased production of biomass, chitin and chitosan by Mucoralean fungi such as Absidia corymbifera [25], R. arrhizus [2,25,28], C. elegans [10] and Syncephalastrum racemosum [9] in culture medium with specific concentrations of corn steep liquor. Santos et al. [10] reported that the increase in biomass production by $C$. elegans is due to the presence of considerable amounts of amino acids (alanine, arginine, histidine, leucine, lysine, tyrosine, phenylalanine) and vitamins (biotin, choline, inositol, niacin, pyridoxine, thiamine) that are essential for the growth of the microorganism. Edwinoliver et al. [29] also suggest that the use of corn steep liquor for lipase production from Aspergillus niger makes the process green, because this substrate is renewable and economically viable on an industrial scale.

Amorim et al. [11] also showed that molasses is an inexpensive carbon source for the growth and production of chitosan by Cunninghamella bertholletiae and they suggest the cultivation of this fungus by using only these carbon sources without nitrogen supplements will result in satisfactory growth and chitosan production. However they have also shown that high concentrations of molasses inhibit the production of chitosan, as observed in this study. Amorim et al. [11] suggested that the concentration 
of sugar was not the only factor responsible for the decrease of chitosan in a medium of molasses. Probably this could be explained by the presence of other substances generated during different production processes which inhibited the enzyme that produces chitosan, as shown by the highest quantities of inorganic impurities detected by thermogravimetric analyses in chitosan preparations obtained from the growth of $C$. bertholletiae cells in molasses.

The controlled use of low cost substrates for replacing or supplementing culture media, generally used with commercial nutrients, can decrease the final value of byproducts, mainly in large scale production, and in addition this alternative promotes the recovery of environments contaminated by agribusiness. This inexpensive source also offers promising advantages for industrial scale production over the chitosan obtained from crustacean shells, because of less use of solvents, heat treatments and simultaneous extraction of chitin and chitosan during the extraction process. The adequate control of the fermentative process can offer a polymer production from fungal biomass continuously, in a short time, with minimum substrate consumption.

\subsection{Characterization of Chitin and Chitosan Extracted from C. elegans and R. arrhizus}

\subsubsection{Infrared Spectroscopy (Deacetylation Degree-DD\%)}

The infrared spectrum of chitin and chitosan from $R$. arrhizus (Figure 6) grown in the culture medium of Assays 1 and 2 were similar to those reported in the literature [5,8,30]. The chitin from $R$. arrhizus showed the presence of two types of amide group (amide I and II). The most significant parts of both chitins were the characteristic bands related to the $\mathrm{CN}$ bond stretching plus $\mathrm{CH}_{3}$ wagging (1311 and $1313 \mathrm{~cm}^{-1}$ ); the $\mathrm{N}-\mathrm{H}$ deformation in the CONH plane, including amide II to (1546 and $1564 \mathrm{~cm}^{-1}$ ); and the carbonyl group stretching, $\mathrm{C}=\mathrm{O}$ (amide I) (1652 and $1654 \mathrm{~cm}^{-1}$ ). In a similar way, chitin shows the specific bands in the amide II region: 1146 and $1171 \mathrm{~cm}^{-1} ; 1371$ and $1377 \mathrm{~cm}^{-1}(\mathrm{C}-\mathrm{O}$ stretching of the $-\mathrm{CH}_{2}-\mathrm{OH}$ group); 1441 and $1453 \mathrm{~cm}^{-1}$, the axial deformation of the amide $\mathrm{C}-\mathrm{N} ; 2933$ and $2917 \mathrm{~cm}^{-1}$, assigned to the $\mathrm{C}-\mathrm{H}$ stretching; and 3441 and $3430 \mathrm{~cm}^{-1}$, corresponding to the axial deformation of $\mathrm{OH}$, which appears overlapping the band of the axial $\mathrm{NH}$ deformation.

The infrared spectrum of chitosan from $R$. arrhizus also presented the most significant amide bands namely $1312-1311,1453-1408$, and $1654-1655 \mathrm{~cm}^{-1}$, but these peaks are less intense than in chitin, mainly the peak of 1654-1655 $\mathrm{cm}^{-1}$. When compared with the infrared spectrum of chitin, the chitosan spectrum showed the band disappearing at $1550 \mathrm{~cm}^{-1}$ (amide II vibrational mode) and the progressive weakening of the band $1655 \mathrm{~cm}^{-1}$ (amide I vibrational mode) as a consequence of the $N$-deacetylation process. Chitosan also presented the bands 2920.97 and $3420.99 \mathrm{~cm}^{-1}$, as observed in the spectrum of chitin obtained in this study. Ebrahimzadeh et al. [30] related that during chitosan production, acetyl is eliminated after hydrolysis and, consequently, the carbonyl band is eliminated in chitosan. However, the infrared spectrum of chitosan from fungal with these amide bands, i.e., the acetyl in the amino group (stretching, $\mathrm{C}=\mathrm{O}$, amide $\mathrm{I}$ ) shows that the chitosan is not completely deacetylated.

The Degree of Deacetylation (DD) is an important parameter associated with the physico-chemical properties of chitosan, because it is linked to the cationic properties of chitosan [4,8,24]. In this article, chitin (Assay 2) presented a DD of $25 \%$ and $40 \%$ and chitosan a DD of $80 \%$ (Assay 7 ) and of $82 \%$ 
(Assay 1) from C. elegans and R. arrhizus, respectively which are similar to the DDs reported in the literature $[11,23,31]$.

\subsubsection{Viscosity and Molecular Weight}

The viscosity and molecular weight of fungal chitosan were 3.40 centipoises and $4.96 \times 10^{3} \mathrm{~g} \cdot \mathrm{mol}^{-1}$ from $R$. arrhizus and $3.79(\mathrm{cP})$ and $5.08 \times 10^{3} \mathrm{~g} \cdot \mathrm{mol}^{-1}$ from $C$. elegans respectively. The result is in agreement with the literature, which reports molar weights ranging from $1.0 \times 10^{3}$ to $9.0 \times 10^{5} \mathrm{~g} \cdot \mathrm{mol}^{-1}[2,11]$. The method for chitin and chitosan extraction used in this study with high temperatures and $\mathrm{NaOH}$ solution may have influenced the breaking of the polymer resulting in chitosan of a lower molecular weight. These results are considerably lower than the viscosity of crab chitosan and similar to other fungal chitosans [24]. Some authors report the viscosity of fungal chitosan from 2.7 to $11.3 \mathrm{cP}$ [30,32] and that of crab shell chitosan between 316.2 and $372.7 \mathrm{cP}$ [24].

The viscosity of chitosan is directly proportional to its molar mass and the results presented in this paper corroborate this statement. The chitosan isolate showed low viscosity and also exhibited lower molar mass, suggesting the molecular weight of fungal chitosan may be lower than that of crab chitosan. These characteristics provide improved solubility in water at physiologically acceptable $\mathrm{pH}$ values which facilitates some applications in the food, medical, agricultural industries as an antimicrobial and preservative agent according to the literature [24,32,33]. Tayela et al. [15] showed that the most bioactive chitosan type for inhibiting the growth of Candida albicans showed the lowest molecular weight (32 kDa) and the highest degree of deacetylation (94\%).

Figure 6. Infrared absorption spectra: (A) Chitosan produced by microbiological R. arrhizus Assay 7; (B) Commercial chitosan (Sigma Aldrich Corp., St. Louis, MO, USA); (C) Chitin produced by microbiological R. arrhizus Assay 2; (D) Commercial chitin (Sigma).
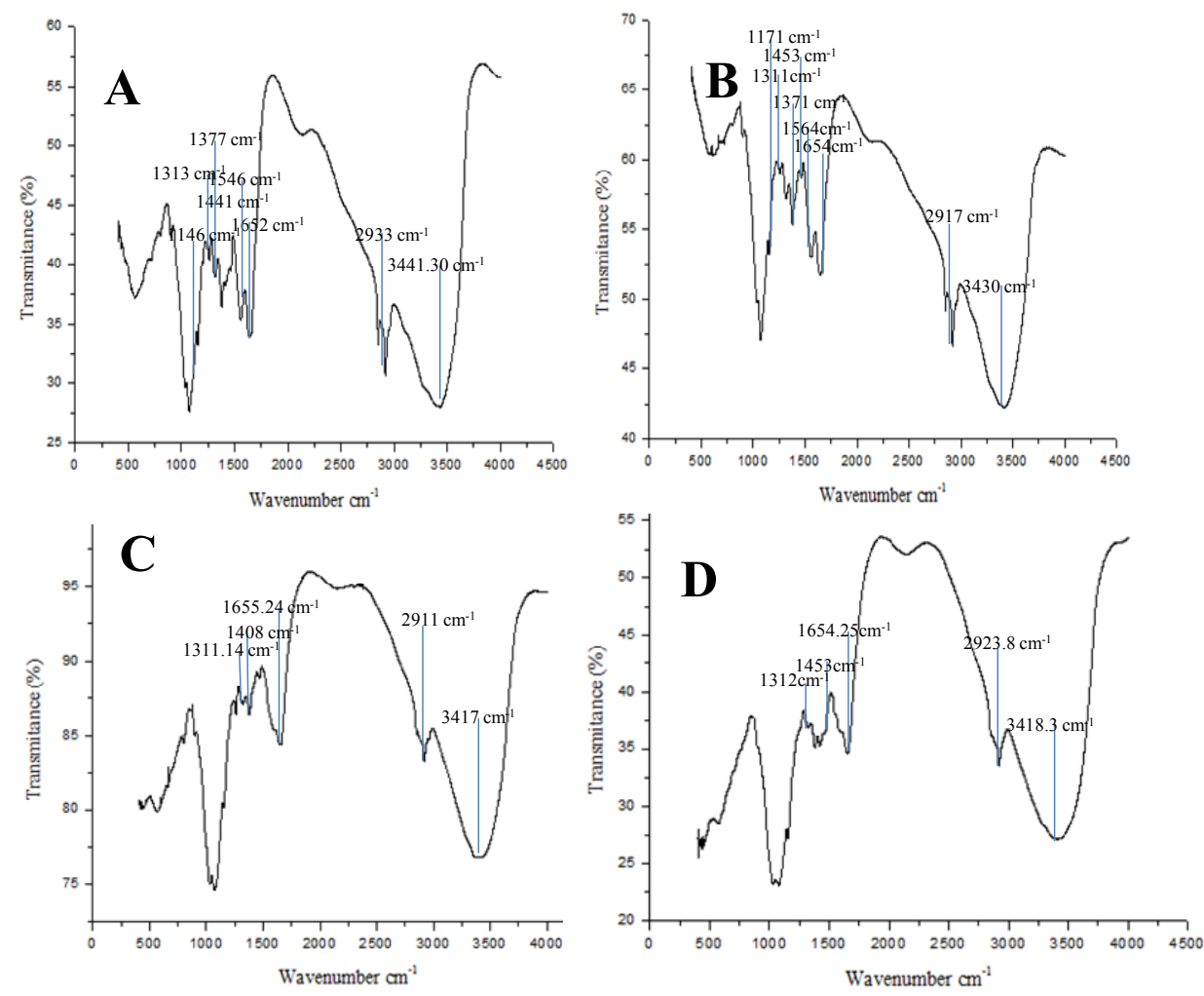


\subsubsection{X-ray Diffraction}

$\mathrm{X}$-ray diffraction is commonly used to determine the polymorphic forms of a compound which has different crystalline structures for which distinct powered X-ray diffraction patterns are obtained [4,31]. Based on these patterns it is possible to observe differences in the spacing of crystal planes and the polymorphic structure, and to provide accurate measurements of the crystalline content, which influences the physical and biological properties of the polymer [4,13,31].

Figure 7 shows the X-ray diffractograms of chitin and chitosan by C. elegans and R. arrhizus in Assays 1 and 2 of the factorial design. The crystallinity indices of these biopolymers were determined from the scattering intensity at two angles, one at $2 \theta=9^{\circ}-10^{\circ}$, representing the diffraction intensity of amorphous regions and another at $2 \theta=19^{\circ}-20^{\circ}$, the diffraction intensity of the crystalline regions. This peak at about $9^{\circ}$ disappeared in both fungal chitins. Probably this suggests a biopolymer with a more crystalline structure. This could also indicate the need of a purification process to obtain a satisfactory biopolymer [34]. The diffraction pattern of chitosan (Figure 5C,D) by C. elegans in Assay 2 (Table 3) showed strong Bragg refractions at angles of $20.0^{\circ}$ and $9.0^{\circ}$ which are two characteristic peaks of chitosan, and are similar to those given in the literature $[4,7]$.

Figure 7. X-ray diffractograms of chitin $(\mathbf{A}, \mathbf{B})$ and chitosan $(\mathbf{C}, \mathbf{D})$ obtained from C. elegans and R. arrhizus biomass, respectively.
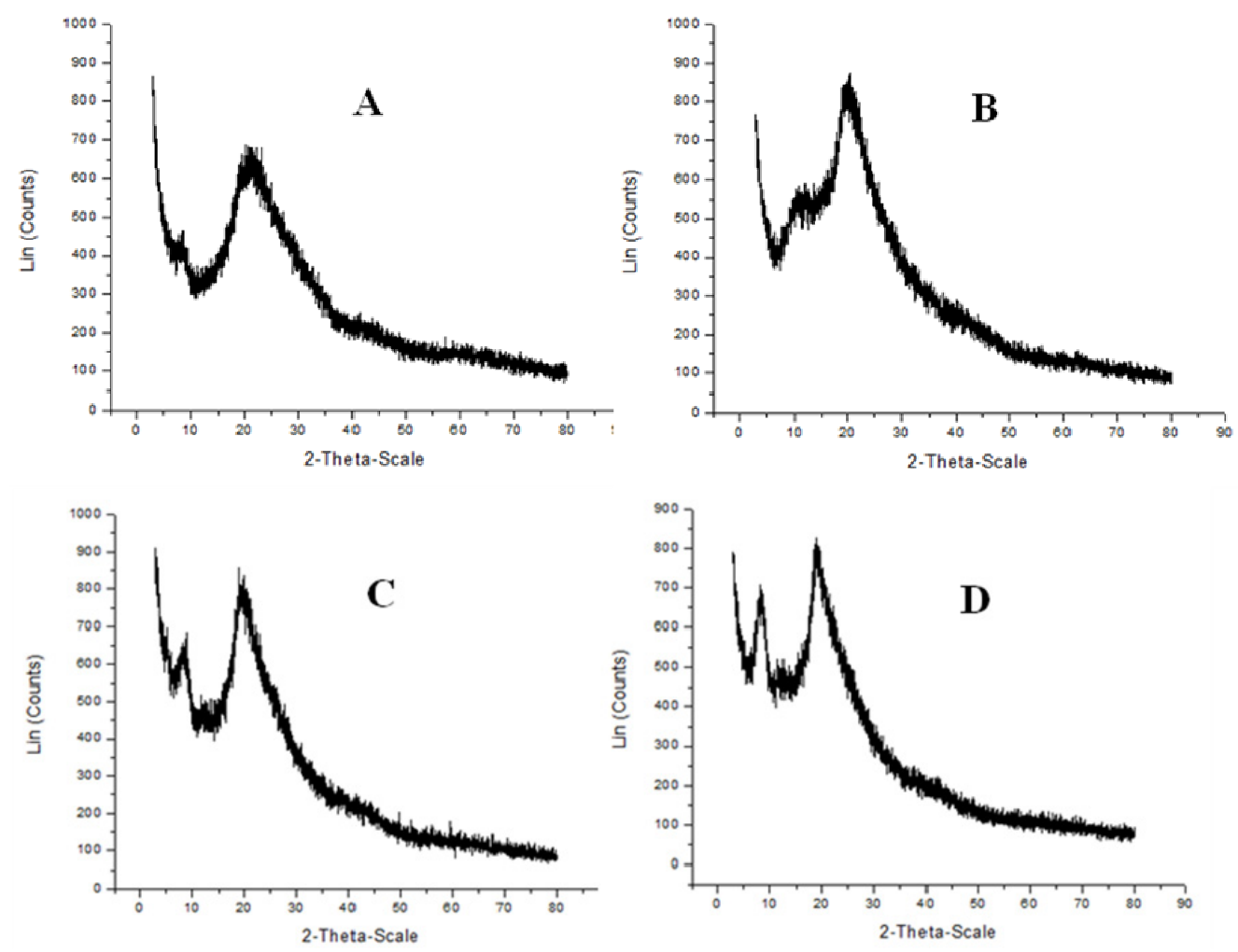

The results from the crystallinity indices were $33.80 \%$ and $32.8 \%$ for chitin, and $20.30 \%$ and $17.8 \%$ for the chitosan obtained by C. elegans and R. arrhizus in Assay 2. Overall, the crystallinity index of chitin was higher than that of chitosan, in which a lower crystallinity of polysaccharides indicates disruption of intra- and inter-molecular hydrogen bonds. The higher crystalline index of chitin reflected: its higher degree of crystallinity and its more ordered structure and the lower crystallinity of 
chitosan indicated disruption of intra- and inter-molecular hydrogen bonds [35]. These results were also lower than those obtained for chitin (45.60\%) and chitosan (23.82\%) from the crustacean standard (data not shown). The results are also supported in the literature [4,31]. Tolaimate et al. [36] suggested that these lower crystallinity indices in chitin and chitosan produced by microbial fermentation might indicate their improved water solubility in comparison with chitin and chitosan prepared from the chemical extraction method, probably due to the more severe extraction conditions during chemical extraction. Some authors also related that the crystallinity index of chitosan is related to its DD function $[4,31]$.

\subsubsection{Scanning Electron Microscopy}

The chitin and chitosan produced by $C$. elegans and R. arrhizus in Assays 1 and 2 were selected for examination by scanning electron microscopy (Figure 8).

Figure 8. Scanning electron microscopy (SEM) photographs of chitin (A) and chitosan (B) produced by $R$. arrhizus and chitosan $(\mathbf{C})$ and chitin $(\mathbf{D})$ produced by $C$. elegans, in Assays 1 and 2 , at $500 \times$ and $1000 \times$ magnification. The measurement bar $=50 \mu \mathrm{M}$.

A

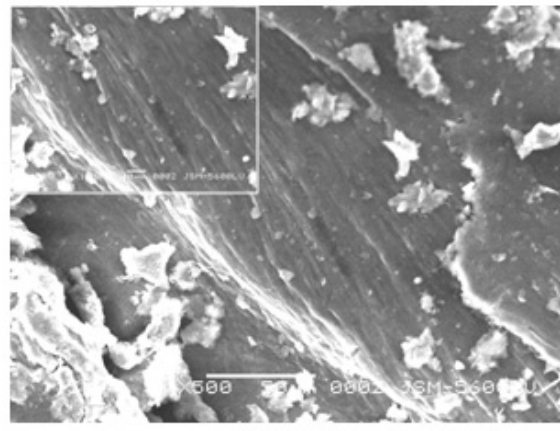

D

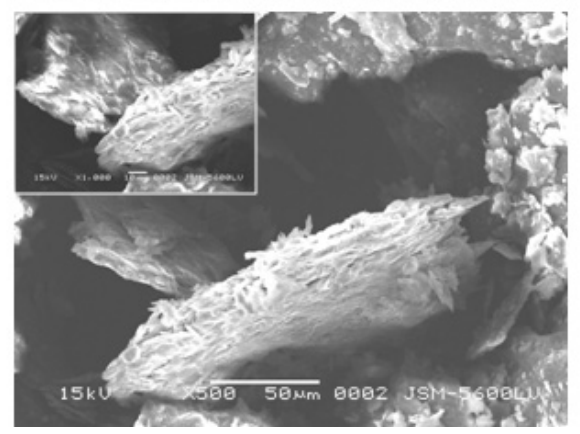

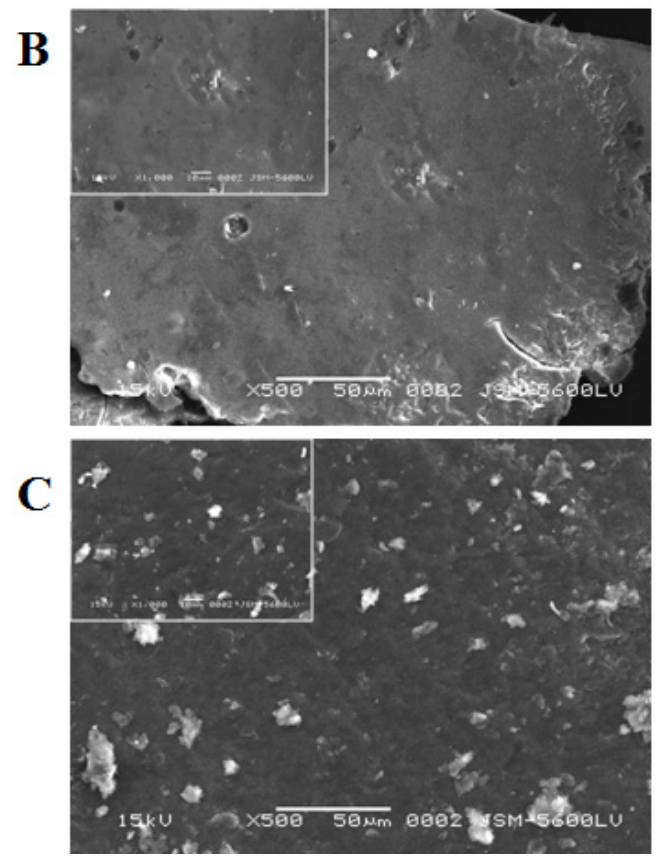

The chitin showed a prominent arranged microfibrillar crystalline structure in SEM (Figure 6A,D) which was absent in the chitosan (Figure 6B,C), as observed by Yen et al. [37], Arbia et al. [5]; and Chan, Chen, and Yuan [38], Yen and Mau [39]. The crystallinity of fungal chitin observed is reinforced with the prominent arranged microfibrillar crystalline structure of this biopolymer in SEM (Figure 5A,D).

Yen et al. [37] related that the crystallinity structure observed between fungal and crab chitins might also be attributed to their different intersheet or intrasheet hydrogen-bonding systems. However, the preview of this microfibrilar structure in the chitin may have arisen from the extraction process of this biopolymer, i.e., the deproteinization step. The fungal chitosan exhibited a more compact, denser structure, with layers of crumbling flake without porosity as observed in crustacean chitosan by Yen et al. [37] and Yen and Mau [39] for fungal chitosan. 


\subsection{Antimicrobial Activity}

The effectiveness of chitosan from $C$. elegans and $R$. arrhizus in inhibiting the growth of Listeria monocytogenes, Staphylococcus aureus, Pseudomonas aeruginosa, Salmonella enterica, Escherichia coli, and Yersinia enterocolitica by determining the MIC and MBC is shown in Table 3. Both chitosans showed identical MIC and MBC for all bacteria assayed. All bacteria grown in presence of acetic acid 1\%. These results are in agreement with those reported in the literature [40,41]. The chitosan samples tested were more effective at inhibiting Gram negative bacteria compared to gram positive ones, except for L. monocytogenes, which showed a higher MIC and MBC.

The antimicrobial activity of chitosan is well documented against a number of pathogenic microorganisms, with MIC varying from $0.01 \%$ to $1 \%[41,42]$. The antibacterial activity of chitosan in vitro depends on the physicochemical characteristics of chitosan and the species, or even the strain of the bacteria tested $[14,43]$.

Table 3. Minimum inhibitory concentration (MIC) and minimum bactericidal concentration (MBC) of chitosan from C. elegans and R. arrhizus against food pathogenic and spoilage bacteria.

\begin{tabular}{c|cc|cc}
\hline \multirow{2}{*}{ Microorganism } & \multicolumn{2}{|c|}{ C. elegans } & \multicolumn{2}{c}{ R. arrhizus } \\
\cline { 2 - 5 } & MIC & MBC & MIC & MBC \\
\hline S. aureus & $300 \mu \mathrm{g} \cdot \mathrm{mL}^{-1}$ & $500 \mu \mathrm{g} \cdot \mathrm{mL}^{-1}$ & $300 \mu \mathrm{g} \cdot \mathrm{mL}^{-1}$ & $500 \mu \mathrm{g} \cdot \mathrm{mL}^{-1}$ \\
E. faecalis & $400 \mu \mathrm{g} \cdot \mathrm{mL}^{-1}$ & $600 \mu \mathrm{g} \cdot \mathrm{mL}^{-1}$ & $400 \mu \mathrm{g} \cdot \mathrm{mL}^{-1}$ & $600 \mu \mathrm{g} \cdot \mathrm{mL}^{-1}$ \\
E. coli & $200 \mu \mathrm{g} \cdot \mathrm{mL}^{-1}$ & $400 \mu \mathrm{g} \cdot \mathrm{mL}^{-1}$ & $200 \mu \mathrm{g} \cdot \mathrm{mL}^{-1}$ & $400 \mu \mathrm{g} \cdot \mathrm{mL}^{-1}$ \\
P. aeruginosa & $200 \mu \mathrm{g} \cdot \mathrm{mL}^{-1}$ & $400 \mu \mathrm{g} \cdot \mathrm{mL}^{-1}$ & $200 \mu \mathrm{g} \cdot \mathrm{mL}^{-1}$ & $400 \mu \mathrm{g} \cdot \mathrm{mL}^{-1}$ \\
L. monocytogenes & $500 \mu \mathrm{g} \cdot \mathrm{mL}^{-1}$ & $1000 \mu \mathrm{g} \cdot \mathrm{mL}^{-1}$ & $500 \mu \mathrm{g} \cdot \mathrm{mL}^{-1}$ & $1000 \mu \mathrm{g} \cdot \mathrm{mL}^{-1}$ \\
Y. enterocolítica & $300 \mu \mathrm{g} \cdot \mathrm{mL}^{-1}$ & $600 \mu \mathrm{g} \cdot \mathrm{mL}^{-1}$ & $300 \mu \mathrm{g} \cdot \mathrm{mL}^{-1}$ & $600 \mu \mathrm{g} \cdot \mathrm{mL}^{-1}$ \\
S. enterica & $300 \mu \mathrm{g} \cdot \mathrm{mL}^{-1}$ & $500 \mu \mathrm{g} \cdot \mathrm{mL}^{-1}$ & $300 \mu \mathrm{g} \cdot \mathrm{mL}^{-1}$ & $500 \mu \mathrm{g} \cdot \mathrm{mL}^{-1}$ \\
\hline
\end{tabular}

Chung et al. [14] investigated the relation between antimicrobial activity of chitosan and the characteristics of the cellular wall of bacteria. The authors verified that chitosan is more efficient as an antibacterial agent against gram-negative bacteria due to the composition of phospholipids and carboxylic acids of the bacterial cellular wall. These results suggest that the effects of chitosan are distinct in the two types of bacteria: in the case of gram-positive ones, the hypothesis is that chitosan of low molecular mass penetrates into bacteria, causing ruptures in the metabolism of these microorganisms. In addition these authors demonstrated that although the hydrophilicity of the cell wall is similar among gram-negative bacteria, the distribution of negative charges on their cell surfaces can be quite different. Most negatively charged cell surfaces have a greater interaction with chitosan. This could explain why the susceptibility of $L$. monocytogenes, S. enterica and $Y$. enterocolitica to both microbial chitosans in this study were different from those of the other gram-negative bacteria tested (Table 3).

Chitosan exhibited antibacterial activity only in an acidic medium, which was usually attributed to the poor solubility of chitosan above $\mathrm{pH} 6.5$ and its more positively charged polycationic molecules with stronger affinity for cells $[44,45]$. Therefore, for the antimicrobial activity, chitosan was dispersed in a solution of $1 \%$ acetic acid. As acetic acid itself has antibacterial activity, a positive control was used, whereby chitosan was replaced with sterile distilled water and $1 \%$ acetic acid, for each 
microorganism to assure that the antimicrobial activity evidenced is attributed to chitosan. Microbial growth was observed in all positive controls. In addition, the viability of the bacterial strains was confirmed by verifying their growth in Brain Heart Infusion (BHI) agar without adding chitosan.

Studies with electronic micrographs demonstrate that in gram-positive bacteria the chitosan weakens or even breaks up the bacterial cellular wall, while in gram-negative bacteria, the cytoplasm is concentrated and the cell interstice is extended. The external membrane of the cellular wall of the gram-negative bacteria consists of lipopolysaccharides (LPS) that provide a hydrophilic surface for the bacterium. The LPS also have anionic groups (phosphate, carboxyl), which contribute to the stability of the LPS through electrostatic interactions with divalent cations. The removal of these cations by chelant agents results in the run down and molecule release of the LPS. On the other hand, the cellular wall of the Gram-positive bacteria consists mainly of peptidoglican (PG) and teichoic acid-TA (polymer polyanion), which are linked covalently to the acid Nacetylmuramic of the PG or anchored in the direction of the cytoplasmic membrane, via glycolipid (lipoteichoic acid-LTA), which provides a binding site with the chitosan, causing functional ruptures in the membrane $[1,18]$.

\section{Experimental Section}

\subsection{Materials}

All reagents used were of analytical grade. The acetic acid and sodium hydroxide were obtained from Vetec (São Paulo, Brazil). The molasses from sugar cane was procured from a local market and corn steep liquor, a byproduct of corn manufacturing industry, was kindly donated by Corn Products do Brasil, Cabo de Santo Agostinho, PE, Brazil. These agroindustrial wastes were used as soluble substrates and the carbon and nitrogen sources in the $2^{2}$ factorial design.

\subsection{Microorganisms and Biomass Production to Obtain Chitin and Chitosan}

C. elegans strain UCP/WFCC 0542 and $R$. arrhizus UCP/WFCC 0402 isolated from mangrove sediments situated in Rio Formoso, PE, Brazil were used. These strains were deposited in the Culture Collection of the Catholic University of Pernambuco, Brazil, registered in the World Federation for Culture Collection (WFCC). The fungi were maintained on Potato Dextrose Agar (PDA) medium at $5{ }^{\circ} \mathrm{C}$ and transferred to a new medium every four months.

For biomass production, both fungi were grown in Petri dishes containing PDA medium at $28{ }^{\circ} \mathrm{C}$ for 8 days until sporulation. Petri dishes containing PDA were inoculated with $1 \mathrm{~mL}$ of the sporangiole suspension $\left(10^{7}\right.$ spores $\left.\cdot \mathrm{mL}^{-1}\right)$ of C. elegans and R. arrhizus and maintained for $18 \mathrm{~h}$ at $28^{\circ} \mathrm{C}$. After the incubation time, 20 discs ( $1 \mathrm{~cm}$ diameter) with mycelium of both fungi were cut from these Petri dishes and inoculated in an Erlenmeyer flask containing $200 \mathrm{~mL}$ of the alternative medium with molasses and corn steep liquor, $\mathrm{pH}$ 5.6. The flasks were incubated at $28{ }^{\circ} \mathrm{C}$ in an orbital shaker at $150 \mathrm{rpm}$, for $96 \mathrm{~h}$. The mycelia were harvested, washed twice in distilled water by filtration, using a nylon membrane silkscreen (120 F). After lyophilization, the biomass was maintained in a vacuum dessicator until constant weight. 


\subsection{Factorial Design}

A $2^{2}$ full factorial design was carried out to analyze the main effects and interactions of molasses $(1 \%-4 \%)$ and corn steep liquor $(2 \%-8 \%)$ on the response variable of biomass, chitin and chitosan yield by $C$. elegans and $R$. arrhizus to select the best condition for producing mycelia and biopolymers in accordance with the variables established (Table 4). Pareto charts were compiled to validate the influence between these agroindustrial wastewaters (independent variables) and the response variables. An estimate of pure experimental error was calculated from four replicates run corresponding to a central point of the complete factorial. The data obtained from the experiments were subjected to statistical analysis by STATISTICA software version 7.0 (StatSoft Inc., Tulsa, OK, USA) and the significance of the results was tested at the $p<0.05$ level.

Table 4. Design matrix for the factorial experiments used to evaluate the influence of two factors (molasses and corn steep liquor) on biomass, chitin and chitosan production by C. elegans UCP/WFCC 0542 and $R$. arrhizus UCP 402/WFCC, with experimental conditions set at the average of two extreme levels.

\begin{tabular}{ccc}
\hline \multirow{2}{*}{ Assays } & \multicolumn{2}{c}{ Factor Levels } \\
\cline { 2 - 3 } & Molasses $^{{ }^{2}}$ & Corn Steep Liquor ${ }^{\mathbf{2}}$ \\
\hline 1 & -1 & -1 \\
2 & +1 & -1 \\
3 & -1 & +1 \\
4 & +1 & +1 \\
5 & 0 & 0 \\
\hline
\end{tabular}

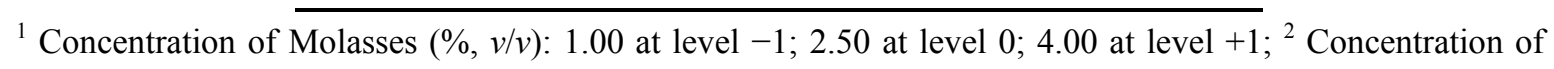
corn steep liquor $(\%, v / v): 2.00$ at level $-1 ; 5.00$ at level $0 ; 8.00$ at level +1 .

\subsection{Chitin and Chitosan Extraction}

Chitin and chitosan were extracted using dry biomass of $C$. elegans and R. arrhizus as described by $\mathrm{Hu}$ et al. [46]. The lyophilized biomass was deproteinized with $1 \mathrm{M} \mathrm{NaOH}$ solution $\left(1: 30 w / v, 121{ }^{\circ} \mathrm{C}\right.$, $15 \mathrm{~min})$. The alkali-insoluble fraction was separated by centrifugation $\left(4000 \times \mathrm{g}, 20^{\circ} \mathrm{C}, 10 \mathrm{~min}\right)$, and treated using $2 \%$ of acetic acid $\left(1: 30 \mathrm{w} / \mathrm{v}, 100{ }^{\circ} \mathrm{C}, 15 \mathrm{~min}\right)$ followed by centrifugation at $4000 \times \mathrm{g}, 20^{\circ} \mathrm{C}$, $15 \mathrm{~min}$. Chitin was considered an acid insoluble material, and the supernatant was alkalized to $\mathrm{pH} 10$, maintained overnight at $5{ }^{\circ} \mathrm{C}$ and centrifuged $\left(4000 \times \mathrm{g}, 20{ }^{\circ} \mathrm{C}, 10 \mathrm{~min}\right)$ so as to precipitate the chitosan. The chitin and chitosan were washed with distilled water four times, freeze-dried, and kept in a dessicator until constant weight.

\subsection{Characterization of Chitin and Chitosan from C. elegans and R. arrhizus}

\subsubsection{Infrared Spectroscopy (Degree of Deacetylation-DD\%)}

The degree of deacetylation (DD\%) for microbial chitin and chitosan was determined using infrared spectroscopy as per Baxter et al. [47], using the absorbance ratio A1655/A3450 and calculated as per Equation (1): 


$$
\mathrm{DD}(\%)=100-[(\mathrm{A} 1655 / \mathrm{A} 3450) \times 115]
$$

A two-milligram sample of fungal chitin and chitosan, which had been dried overnight at $60{ }^{\circ} \mathrm{C}$ under reduced pressure was thoroughly blended with $100 \mathrm{mg}$ of $\mathrm{KBr}$ to produce $0.5 \mathrm{~mm}$ thick disks. The disks were dried for $24 \mathrm{~h}$ at $110^{\circ} \mathrm{C}$ under reduced pressure. An infrared spectrometry reading was taken with a Bruker 66 Spectrometer (Bruker Corporation Inc., Billerica, MA, USA), using 100-mg KBr disks for reference.

\subsubsection{Viscosity and Molecular Weights of Chitosan}

The viscosity of $1 \%$ chitosan in buffer solution (acetic acid/sodium acetate, $\mathrm{pH} \sim 4.5$ ), was determined using a Brookfield digital Rheometer (Model DV-II, Brook Engineering laboratories, Inc., Stoughton, MA, USA) at $25^{\circ} \mathrm{C}$, Spindle CPE-40, $0.5 \mathrm{~mL}$ sample volume [8].

The molecular weight of chitosan was determined using an AVS-350 viscometer (Schott-Geräte, Quebec City, QC, Canada), type/capillary: Cannon-Fenske $d_{\text {inside }}=1.01 \mathrm{~mm}$, at $25^{\circ} \mathrm{C}$. After obtaining the intrinsic viscosity from tables, $K$ and $a$, were obtained for HAc/NaAc. $K=0.076, a=0.76$. The flow time was determined in seconds. Using the Mark-Houwink equation, the average viscosimetric molecular weight was expressed in $\mathrm{g} \cdot \mathrm{mol}^{-1}$ [48]. See Equation (2):

$$
[\eta]=K\left(\bar{M}_{v}\right)^{a}
$$

\subsubsection{Crystallinity Index}

The X-ray diffractograms of chitin and chitosan were obtained in the X-ray Laboratory of the Physics Department Federal University of Pernambuco-UFPE. The measurement was taken using SIEMENS Model 5000 D X-ray equipment (Siemens Corporation, Aubrey, TX, USA), $\mathrm{Cu} \mathrm{K \alpha}$ radiation with $\lambda=1.542 \AA$, in a scanning range between $4^{\circ}$ and $50^{\circ}$ with a rate of $0.02 \mathrm{~min}^{-1}$. The interplanar distance was determined by the half height width of the peak of greatest intensity (IC). The crystallinity index (ICR) was determined using the following equation:

$$
\text { Crystallinity index }(\%)=100\left\{\left[I\left(\theta_{\mathrm{c}}\right)-I\left(\theta_{\mathrm{a}}\right)\right] / I\left(\theta_{\mathrm{c}}\right)\right\}
$$

where $I\left(\theta_{\mathrm{c}}\right)$ is the relative intensity of the crystalline regions $\left(2 \theta=20^{\circ}\right)$ and $I\left(\theta_{\mathrm{a}}\right)$ corresponds to amorphous regions $\left(2 \theta=9^{\circ}\right)$ for chitosan.

\subsubsection{Scanning Electron Microscopy}

The dried sample was ground under vacuum using a sputter coater and its surface was observed using a scanning electron microscope Series XL 30 (Umax) ESEM (Env. Scan. Electron Micros, Jeol, Tokyo, Japan) with tungsten filament, at $20 \mathrm{kV}$ accelerating voltage.

\subsection{Bacterial Strains and Culture Conditions for the Antimicrobial Assay}

L. monocytogenes ATCC 7664, P. aeruginosa ATCC 9027, S. enterica ATCC 6017, and Y. enterocolítica ATCC 9610 for antimicrobial assay were provided by FIOCRUZ, Rio de Janeiro, Brazil. S. aureus ATCC 6538, E. faecalis ATCC 29212 and E. coli ATCC 8739 were donated by the Antibiotics Institute, UFPE (Recife, Brazil). Stock cultures were kept on Muller Hinton agar slants 
with blood added $(5 \% v / v)$ at $4{ }^{\circ} \mathrm{C}$. Inoculums used in the experimental assays were obtained from cultures grown overnight (18 h) in Brain Heart Infusion broth (DIFCO Laboratories, Detroit, MI, USA) at $37^{\circ} \mathrm{C}$. After incubation, the bacterial cells were separated from the growth medium by centrifugation at $10,000 \times \mathrm{g}$ for $15 \mathrm{~min}$ at $4{ }^{\circ} \mathrm{C}$, washed thrice in buffer $\mathrm{KCl}\left(0.05 \mathrm{M} \mathrm{KCl}, 1.0 \mathrm{mM} \mathrm{KH} \mathrm{PO}_{4}, 1.0 \mathrm{mM}\right.$ $\mathrm{CaCl}_{2}, 0.1 \mathrm{mM} \mathrm{MgCl}_{2}, \mathrm{pH} 6.0$ ), and resuspended in buffer $\mathrm{KCl}$. Suspensions were adjusted so that the optical density (OD) at $660 \mathrm{~nm}$ was 1.5 , which provided bacterial inoculum of approximately $5 \times 10^{8}$ Colony Forming Unity per $\mathrm{mL}\left(\mathrm{CFU} \cdot \mathrm{mL}^{-1}\right)$.

\subsection{Chitosan Solution Preparation}

Chitosan from $C$. elegans and $R$. arrhizus were solubilized in a solution of $1 \%$ acetic acid at concentrations to $20 \mathrm{mg} / \mathrm{mL}(w / v)$. The $\mathrm{pH}$ of the solutions were adjusted to $\mathrm{pH} 5.8$ using $\mathrm{HCl}$ and $\mathrm{NaOH}$.

\subsection{Antimicrobial Activity}

Minimum inhibitory concentration (MIC) and minimum bactericidal concentration (MBC) of chitosan on the assayed bacteria were carried out using the broth dilution method (Heilman test) as described by Chambrevil; Marmonier [49]. For this, a $0.1 \mathrm{~mL}$ aliquot of bacterial inoculum was inoculated into screw-capped $13 \times 130 \mathrm{~mm}$ sterile tubes containing $0.9 \mathrm{~mL}$ of BHI broth containing the desired chitosan concentration $\left(5000-50 \mu \mathrm{g} \cdot \mathrm{mL}^{-1}\right)$ followed by shaking using Vortex for $30 \mathrm{~s}$. The system was incubated at $37{ }^{\circ} \mathrm{C}$ for $24 \mathrm{~h}$ and the MIC was defined as the lowest chitosan concentration providing no visible growth (turbidity) and the $\mathrm{MBC}$ was the lowest chitosan concentration able to cause a $99.9 \%$ kill rate of the initial inoculum. MBC was found by inoculating a $25-\mu \mathrm{L}$ aliquot of the chitosan-treated Assay into sterile Muller Hinton agar Petri dishes and was followed by incubation at $37{ }^{\circ} \mathrm{C}$ for $48 \mathrm{~h}$. For positive control, chitosan was replaced with sterile distilled water and $1 \%$ acetic acid. The assays were conducted in triplicate and the results expressed as average values. Also, the viability of the bacterial strains was assessed by verifying their capacity to grow in a Muller-Hinton agar without adding chitosan.

\section{Conclusions}

These results suggest a new economic culture medium to improve chitin and chitosan production from mycelial biomass by $C$. elegans and $R$. arrhizus with a low molecular weight and degree of deacetylation of approximately $80 \%$. The data obtained from this research point out that the selection of chitosan is one of the important factors to consider before applying chitosan in medical sectors, considering the antimicrobial potential of chitosan against pathogenic bacteria. Therefore chitosan shows great promise as an alternative natural antimicrobial agent against gram-positive and gram-negative bacteria. All in all, it is expected that much progress will be made in reaching the final goal of developing the mechanism of chitosan against bacterial pathogens at the molecular level.

\section{Acknowledgments}

This research study was supported financially by CNPq (National Council for Scientific and Technological Development, Brasilia-D.F., Brazil), FACEPE (Foundation for the Support of Science 
and Technology of the State of Pernambuco, Recife-PE, Brazil) and CAPES (Coordination for the Improvement of Higher Level Education, Brasília-D.F., Brazil). The authors are grateful to Corn Products (Cabo de Santo Agostinho-PE, Brazil) who kindly provided the substrate corn steep liquor. The authors are also grateful to the Nucleus of Research in Environmental Sciences (NPCIAMB), Catholic University of Pernambuco (Recife-PE, Brazil) for the use of its laboratories.

\section{Author Contributions}

Lúcia Raquel Ramos Berger: Development and execution of the all subjects, factorial designs, writing and discussion of the results (Thesis).

Thayza C. Montenegro Stamford: Co-superviser L.R.R.Berguer, X-Ray Diffraction, revision and discussion of the results.

Thatiana Montenegro Stamford-Arnaud: Support to Molecular Weight and deacetylation degree of chitosan.

Sergio Roberto Cabral de Alcântara: Support to antimicrobial activity determination.

Antonio Cardoso da Silva: Support to Crystallinity Index of chitin and chitosan.

Adamares Marques da Silva: Support to acetylation and deacetylation degree.

Aline Elesbão do Nascimento: Support to Scanning Electron Microscopy method.

Galba M. Campos-Takaki: Superviser L.R.R.Berguer, scope of the paper, Fermentative processes, revision and discussion of the results.

\section{Conflicts of Interest}

The authors declare no conflict of interest.

\section{References}

1. Stamford, T.C.M.; Stamford-Arnaud, T.M.; Cavalcante, H.M.M.; Macedo, R.O.; Campos-Takaki, G.M. Microbiological chitosan: Potential application as anticariogenic agent. In Practical Applications in Biomedical Engineering, 1st ed.; Andrade, A.O., Pereira, A.A., Naves, E.L.M., Soares, A.B., Eds.; InTech: Rijeka, Croatia, 2013; Volume 9, pp. 229-244.

2. Berger, L.R.R.; Cardoso, A.; Stamford, T.C.M.; Cavalcante, H.M.M.; Macedo, R.O.; Campos-Takaki, G.M. Agroindustrial waste as alternative medium in the production of chitin and chitosan by Rhizopus arrhizus -A factorial design. Asian Chitin J. 2011, 7, 83-90.

3. Latha, S.; Suresh, G. Studies on chitosan production from different fungal mycelium. Int. J. Curr. Biotechnol. 2013, 1, 9-11.

4. Fai, A.E.C.; Stamford, T.C.M.; Stamford-Arnaud, T.M.; Santa-Cruz, P.A.; Silva, M.C.F.; Campos-Takaki, G.M.; Stamford, T.L.M. Physico-chemical characteristics and functional properties of chitin and chitosan produced by Mucor circinelloides using yam bean as substrate. Molecules 2011, 16, 7143-7154.

5. Arbia, W.; Adour, L.; Amrane, A.; Lounici, H. Optimization of medium composition for enhanced chitin extraction from Parapenaeus longirostris by Lactobacillus helveticus using response surface methodology. Food Hydrocoll. 2013, 31, 392-403. 
6. Karimi, K.; Zamani, A. Mucor indicus: Biology and industrial application perspectives: A review. Biotechnol. Adv. 2013, 3, 466-481.

7. Wang, W.; Du Y.; Qiu, Y.; Wang, X.; Hu, Y.; Yang, J.; Cai, J.; Kennedy, J.F. A new green technology for direct production of low molecular weight chitosan. Carbohydr. Polym. 2008, 74, $127-132$.

8. Stamford, T.C.M.; Stamford, T.L.M.; Stamford, N.P.; Neto, B.B.; Campos-Takaki, G.M. Growth of Cunninghamella elegans UCP 542 and production of chitin and chitosan using yam bean medium. Electron. J. Biotechnol. 2007, 10, 61-69.

9. Batista, A.C.L.; Silva, M.C.F.; Batista, J.B.; Nascimento, A.E.; Campos-Takaki, G.M. Eco-friendly chitosan production by Syncephalastrum racemosum and application to the removal of acid orange 7 (AO7) from wastewaters. Molecules 2013, 18, 7646-7660.

10. Santos, E.R.; Silva, M.C.F.; Souza, P.M.; Silva, A.C.; Paiva, S.C.; Albuquerque, C.D.C.; Nascimento, A.E.; Okada, K.; Campos-Takaki, G.M. Enhancement of Cunninghamella elegans UCP/WFCC 0542 biomass and chitosan with amino acid supply. Molecules 2013, 18, 10095-10107.

11. Amorim, R.V.S.; Pedrosa, R.P.; Kazutaka, F.; Martínez, C.R.; Ledingham, W.M.; Campos-Takaki, G.M. Alternative carbon sources from sugar cane process for submerged cultivation of Cunninghamella bertholletiae to produce chitosan. Food Technol. Biotechnol. 2006, 44, 519-523.

12. Moussa, S.H.; Tayel, A.A.; Al-Hassan A.A.; Farouk, A. Tetrazolium/Formazan test as an efficient method to determine fungal chitosan antimicrobial activity. J. Mycol. 2013, 753692:1-753692:7.

13. Gavhane, Y.N.; Gurav, A.S.; Yadav, A.V. Chitosan and its applications: A review of the literature. Int. J. Biomed. Pharm. Sci. 2013, 4, 312-331.

14. Chung, Y.-C.; Su, Y.-A.; Chen, C.-C.; Jia, G.; Wang, H.-L.; Wu, J.C.G.; Lin, J.G. Relationship between antibacterial activity of chitosan and surface characteristics of cell wall. Acta Pharm. Sin. 2004, 25, 932-936.

15. Tayel, A.A.; Moussa, S.; el-Tras, W.F.; Knittel, D.; Opwis, K.; Schollmeyer, E. Anticandidal action of fungal chitosan against Candida albicans. Int. J. Biol. Macromol. 2010, 47, 454-457.

16. Devlieghere, F.; Vermeiren, A.; Debevere, J. Chitosan: Antimicrobial activity, interactions with food components and applicability as a coating on fruit and vegetables. Food Microbiol. 2004, 21, $703-714$.

17. Xia, W.; Liu, P.; Zhang, J.; Chen, J. Biological activities of chitosan and chitooligosaccharides. Food Hydrocoll. 2011, 25, 170-179.

18. Kong, M.; Chen, X.G.; Xing, K.; Park, H.J. Antimicrobial properties of chitosan and mode of action: A state of the art review. Int. J. Food Microbiol. 2010, 144, 51-63.

19. Nwe, N.; Chandrkrachang, S.; Stevens, W.F.; Maw, T.; Tan, T.K.; Khor, E.; Wong, S.M. Production of fungal chitosan by solid state and submerged fermentation. Carbohydr. Polym. 2002, 49, 235-237.

20. Nwe, N.; Stevens, W.F. Effect of urea on fungal chitosan production in solid substrate fermentation. Process Biochem. 2004, 39, 1639-1642.

21. Zhao, Y.; Park, R.D.; Muzzarelli, R.A.A. Chitin Deacetylase: Properties and applications. Mar. Drugs 2010, 8, 24-46. 
22. Antunes, A.A.; Berger, L.R.R.; Antunens, M.M.; Silva, M.C.F.; Souza, P.M.; Silva, A.C.; Albuquerque, C.D.C.; Campos-Takaki, G.M. Production of chitin and chitosan by Absidia corymbifera using industrial candy waste as alternative medium. Asian Chitin J. 2012, 8, 1-6.

23. White, S.A.; Farina, P.R.; Fultong, L. Production and isolation of chitosan from Mucor rouxii. Appl. Environ. Microbiol. 1979, 38, 323-328.

24. Pochanavanich, P.; Suntornsuk, W. Fungal chitosan production and its characterization. Lett. Appl. Microbiol. 2002, 35, 17-21.

25. Pareek, N.; Singh, R.P.; Ghosh, S. Optimization of medium composition for enhanced chitin deacetylase production by mutant Penicillium oxalicum SAEM-51 using response surface methodology under submerged fermentation. Process Biochem. 2011, 46, 1693-1697.

26. Lins, C.I.M.; Cardoso A.; Silva, M.C.F.; Batista, A.C L.; Jara, A.M.A.T.; Berger, L.R.R.; Santos, E.R.; Marques da Silva, A.; Campos-Takaki, G.M. Evaluation of chitin and chitosan by different extraction methods from mucoralean fungi biomass. Asian Chitin J. 2010, 6, 5-8.

27. Nadarajah, K.; Kader, J.; Mohd, M.; Paul, D.C. Production of chitosan by fungi. J. Biol. Sci. 2001, 4, 263-265.

28. Cardoso, A.; Lins, C.I.M.; Santos, E.R.; Silva, M.C.F.; Campos-Takaki, G.M. Microbial enhance of chitosan production by Rhizopus arrhizus using agroindustrial substrates. Molecules 2012, 17, 4904-4914.

29. Edwinoliver, N.G.; Thirunavukarasu, K.; Purushothaman, S.; Rose, C.; Gowthaman, M.K.; Kamini, N.R. Corn steep liquor as a nutrition adjunct for the production of Aspergillus niger lipase and hydrolysis of oils thereof. J. Agric. Food Chem. 2009, 25, 10658-10663.

30. Ebrahimzadeh, M.A.; Chabra, A.; Gharaei-Fathabad, E.; Pourmorad, F. Preparation of chitosan from Penicillium spp. and determination of their degree of deacetylation. Indian J. Biotechnol. 2013, 12, 231-235.

31. Chatterjee, S.; Adhya, M.; Guha, A.K.; Chatterjee, B.P. Chitosan from Mucor rouxii: Production and physico-chemical characterization. Process Biochem. 2005, 40, 395-400.

32. Omogbai, B.A.; Ikenebomeh, M. Solid-state fermentative production and bioactivity of fungal chitosan. J. Microbiol. Biotechnol. Food Sci. 2013, 3, 172-175.

33. Tikhonov, V.E.; Stepnova, E.A.; Babak, V.G.; Yamskov, I.A.; Palma-Guerrero, J.; Jansson, H.B.; Lopez-Llorca, L.V.; Salinas, J.; Gerasimenko, D.V.; Avdienko, I.D.; et al. Bactericidal and antifungal activities of a low molecular weight chitosan and its $\mathrm{N}$-/2(3)-(dodec-2-enyl)succinoyl/ -derivatives. Carbohydr. Polym. 2006, 64, 66-72.

34. Zhang, H.; Yanga, S.; Fanga, J.; Denga, Y.; Wanga, D.; Zhao, Y. Optimization of the fermentation conditions of Rhizopus japonicas M193 for the production of chitin deacetylase and chitosan. Carbohydr. Polym. 2014, 101, 57-67.

35. Pareek, N.; Vivekanand, V.; Agarwal, P.; Saroj, S.; Singh, R.P. Bioconversion to chitosan: A two stage process employing chitin deacetylase from Penicillium oxalicum SAEM-51. Carbohydr. Polym. 2013, 96, 417-425.

36. Tolaimate, A.; Desbrieres, J.; Rhazi, A.; Vincendon, M.; Vottero, P. On the influence of deacetylation process on the physicochemical characteristics of chitosan from squid chitin. Polymer 2000, 41, 2463-2469. 
37. Yen, M.-T.; Yang, J.-H.; Mau, J.-L. Physicochemical characterization of chitin and chitosan from crab shells. Carbohydr. Polym. 2009, 75, 15-21.

38. Chan, H.-Y.; Chen, M.-H.; Yuan, G.-F. Fungal chitosan. Fungal Sci. 2001, 16, 39-52.

39. Yen, M.-T.; Mau, J.-L. Physico-chemical characterization of fungal chitosan from shiitake stipes. LWT-Food Sci. Technol. 2007, 40, 472-479.

40. Kanatt, S.R.; Chander, R.; Sharma, A. Chitosan glucose complex-A novel food preservative. Food Chem. 2008, 106, 521-528.

41. Kanatt, S.R.; Chander, R.; Sharma, A. Chitosan and mint mixture: A new preservative for meat and meat products. Food Chem. 2008, 107, 845-852.

42. Sagoo, S.K.; Board, R.; Roller, S. Chitosan potentiates the antimicrobial action of sodium benzoate on spoilage yeasts. Lett. Appl. Microbiol. 2002, 34, 168-172.

43. Tsai, G.-J.; Hwang, S.-P. In vitro and in vivo antibacterial activity of shrimp chitosan against some intestinal bacteria. Fish. Sci. 2004, 70, 675-681.

44. Quin, C.; Li, H.; Xiao, Q.; Liu, Y.; Zhu, J.; Du, Y. Water-solubility of chitosan and its antimicrobial activity. Carbohydr. Polym. 2006, 63, 367-374.

45. Liu, H.; Du, Y.; Yang, J.; Zhu, H. Structural characterization and antimicrobial activity of chitosan/betaine derivative complex. Carbohydr. Polym. 2004, 55, 291-297.

46. Hu, K.-J.; Yeung, K.W.; Ho, K.P.; Hu, J.L. Rapid extraction of high-quality chitosan from mycelia of Absidia glauca. J. Food Biochem. 1999, 23, 187-196.

47. Baxter, A.; Dillon, M.; Taylor, K.D.A.; Roberts, G.A.F. Improved method for I.R. determination of the degree of $N$-acetylation of chitosan. Int. J. Biol. Macromol. 1992, 14, 166-169.

48. Dos Santos, J.E.; Soares, J.P.; Dockal, E.R.; Filho, S.P.C.; Cavalheiro, E.T.G. Caracterização de quitosanas comerciais de diferentes origens. Polímero: Ciênc. Tecnol. 2003, 13, 242-249.

49. Chambrevil, G.; Marmonier, A.A. Contrôle de la thérapeutique antibiotique. In Bactériologie Médicale; Carbonnelle, B., Denis, F., Mormonier, A., Pinon, G., Vargues, R., Eds; SIMEP: Paris, France, 1987.

(C) 2014 by the authors; licensee MDPI, Basel, Switzerland. This article is an open access article distributed under the terms and conditions of the Creative Commons Attribution license (http://creativecommons.org/licenses/by/3.0/). 